\title{
Fluorine F 18-AIF-NOTA-neurotensin
}

National Cancer Institute

\section{Source}

National Cancer Institute. Fluorine F18-AIF-NOTA-neurotensin. NCI Thesaurus. Code C155972.

A radioconjug ate containing neurotensin (NT) linked to the radionuclide fluorine $F 18$ (18F), by the macrocyclic chelating agent, 1,4,7-triazacyclononane- $\mathrm{N}, \mathrm{N}^{\prime}, \mathrm{N}^{\prime}$--triacetic acid (NOTA), through a method that first couples $18 \mathrm{~F}$ to aluminum (Al), with potential use in diagnostic imaging using positron emission tomography/computed tomography (PET/CT). Upon administration of fluorine F 18-Al-NOTA-neurotensin, the ligand moiety targets and binds to the neurotensin receptor (NTR). Upon PET/CT, NTR-expressing tumor cells can then be visualized and NTR tumor cell expression can be assessed, as well as the diagnosis and stage of cancer. The neuropeptide NT is overexpressed in certain types of cancers and plays a key role in tumor cell proliferation. 